\title{
Análisis De La Práctica Creativa Musical En Educación Primaria Como Base Para El Diseño Y Desarrollo De Una Herramienta Metodológica De Evaluación Didáctica
}

\author{
Luis del Barrio Aranda, (PhD) \\ University of Zaragoza, Faculty of Education, Spain
}

doi: 10.19044/esj.2017.v13n19p1 URL:http://dx.doi.org/10.19044/esj.2017.v13n19p1

\begin{abstract}
This study focuses on the analysis of musical creativity as a capacity of self didactics favoring the development of the autonomy of the student in Primary education. Our goal is to design and develop a tool of evaluation of the musical knowledge of the student in creative practice that serves as the basis for the orientation of the educational process. To do this, we carry out an ethnographic research with a class group of 26 pupils of fourth of Primary school who performed sixty creative tasks during two school years. The results obtained from the analysis of the works of children have shown that systematic creative activity stimulates musical thinking, hearing, musicalverbal expression and critical analysis and provides the student a greater confidence and security in the undertaking of new challenges. At the end of the study, analysis of productions has improved the design of a methodological tool capable of analyzing the musical knowledge of the student in a creative educational process.
\end{abstract}

Keywords: Musical creativity, didactic assessment, Primary Education

\section{Resumen}

Este estudio se centra en el análisis de la creatividad musical como una capacidad de autodidaxia que favorece el desarrollo de la autonomía del alumno en Educación Primaria. Nuestro objetivo es diseñar y desarrollar una herramienta de evaluación del conocimiento musical del alumno en la práctica creativa que sirva de base para la orientación del proceso educativo. Para ello, realizamos una investigación etnográfica con un grupo-clase de 26 niños de cuarto de educación primaria quienes durante dos cursos escolares realizaron sesenta tareas creativas. Los resultados obtenidos del análisis de las obras de los niños han demostrado que la actividad creativa sistemática estimula el pensamiento musical, la capacidad auditiva, la expresión verbal 
musical y el análisis crítico y proporciona al alumno una mayor confianza y seguridad en el emprendimiento de nuevos retos. Al término del estudio, el análisis de las producciones ha favorecido el diseño de una herramienta metodológica capaz de analizar el conocimiento musical del alumno en un proceso educativo creativo.

Palabras-clave: Creatividad musical, evaluación didáctica, Educación Primaria

\section{Introducción}

La música estimula la vida interior del individuo apelando las principales facultades humanas como la voluntad, la sensibilidad, el amor, la inteligencia y la imaginación creadora (Willems, 1976, 2011). La evolución de la pedagogía musical en la Educación Primaria y las recientes investigaciones integran junto al estudio de los elementos musicales, la naturaleza humana de los procesos físicos, cognitivos, afectivos y sociales que la definen y el desarrollo de los beneficios que la participación activa y creativa reporta en el bienestar personal, el reto musical, la satisfacción y la integración social del alumno (Pitts, 2005; Finnegan, 2007; Hallam et al., 2012).

En este sentido, y en la línea de M. Rodríguez (2005) las necesidades más profundas y vitales de expresión son satisfechas cuando el sujeto se dedica a actividades orientadas hacia metas diseñadas y buscadas por él mismo. La consideración educativa de la sensación como un medio de conocimiento implica el acceso natural al mismo desde lo sensorial, proceso que Cosachov (2000) denomina sentirpensar, ampliado por Díaz (2007) sentirpensar-crear.

Desde una dimensión educativa, la práctica creativa musical alberga este proceso sensocognitivo de promoción de procesos mentales, con el establecimiento de secuencias coherentes desde el punto de vista psicológico, en el que el alumno construye el conocimiento mediante la exploración, la manipulación y la producción sonora. El valor educativo de la creación musical en cualquier nivel de aprendizaje requiere la comprensión musical del docente sobre el trabajo creativo del alumno. Así, para el desarrollo educativo del creador resulta de vital importancia que el producto sea escuchado por alguien más que por él mismo. La comprensión docente de las producciones de los niños, o esforzarse al máximo para lograrlo, resulta fundamental para la calidad de cualquier interacción docente que pretenda ayudar al alumno en su progreso educativo. Por ello, la educación de la audición, tanto del maestro como de los niños, constituye la base del desarrollo del trabajo creativo (Glover, 2004). En este contexto el maestro debe comportarse como un auténtico dinamizador del proceso educativo 
alentando y fomentando en el niño valores relacionados con la participación, el esfuerzo y el respeto hacia las producciones propias y ajenas, pero también, evitando desviar el proceso compositivo hacia modelos o estereotipos que inhiban la iniciativa y la originalidad del niño. La activación del pensamiento del alumno en la práctica creativa permite ubicar esta actividad musical en un contexto de audición atenta y de autoexamen crítico dentro de un modelo educativo musical construccionista (Froehlich, 2011), en el que el alumno participa activamente en la resolución de problemas basados en la propia acción, entendidos como experiencias significativas de aprendizaje.

Desde una dimensión cognitiva tomando como referencia los estudios de Sloboda (1985), los procesos psicológicos que subyacen al ejercicio de la creación musical poseen dos características fundamentales: un punto de partida, basado en un plan superordinado del individuo, entendido como un conjunto de ideas, esquemas o representaciones mentales, que forman parte del bagaje experiencial del individuo y guía posteriormente la elaboración detallada de la creación musical, y un desarrollo marcado por el carácter provisorio del plan diseñado que le permite al individuo cambiar rápidamente, según el modo de proceder en la elaboración. Por su parte, la consideración educativa de la práctica creativa musical requiere el conocimiento de las fases que forman este proceso productivo (Delalande, 2013): la exploración o etapa de manipulación de nuevos elementos y el examen de sus propiedades; el descubrimiento, entendido como el momento fortuito que despierta la atención del alumno sobre un elemento, debido a su carácter evocador o su estructura formal, y se convierte en el germen del proceso y el producto creativo; el proyecto, marcado por consignas que orientan la elaboración y la ordenación de elementos que dan como resultado una producción final y, por último, la realización o la ejecución del proyecto que representa la fase de interpretación en la que se admite la incorporación de nuevos elementos o descubrimientos que puedan surgir en aquel momento.

\section{De la capacidad audioperceptiva a la escucha creativa}

La educación auditiva del niño desde los primeros años constituye la base fundamental para el desarrollo de su musicalidad. A lo largo de los años encontramos que uno de los principales problemas en el aprendizaje musical del individuo ha sido, y sigue siendo, el escaso valor que en el proceso de enseñanza se le ha otorgado a la formación auditiva. En un sistema tradicional, la enseñanza de la música se ha relacionado más con el dominio de la lectura y la escritura de una simbología abstracta, que con la comprensión del fluir sonoro. Por tanto, la formación auditiva se ha basado en procedimientos como la imitación, la memorización y la decodificación 
de los signos mediante la interpretación instrumental, pero no ha dedicado tiempo a la formación del oído interno, ni a la comprensión del hecho musical tan beneficioso para el desarrollo auditivo. En este sentido y de acuerdo con López Arenosa (2008), no podemos hablar de formación del oído si no hemos interiorizado imágenes sonoras capaces de reproducir aún sin sonar. Necesitamos un trabajo transitorio entre el sonido y la adquisición de un código musical que pasa por la vivencia y la práctica creativa de la representación no convencional del sonido mediante el movimiento y el dibujo, asignando un significado al perfil melódico. De tal modo, enriquecemos la escucha desde que asociamos un acto creativo corporal a la música, desde que hacemos preceder el hacer al escuchar (Delalande, 1995).

En el proceso auditivo los sentimientos proporcionan un significado afectivo a los sonidos y a las estructuras tonales convirtiendo la vivencia musical en una experiencia afectiva que lleva a cada individuo ante una música determinada a absorber, escuchar, interpretar y recrear el sonido de forma personal (Waisburd y Erdmenger, 2007). Para favorecer la capacidad auditiva musical del niño es preciso: educar la experimentación sonora con el entrenamiento en el acto de la escucha; trabajar la atención y la sensibilidad hacia el sonido, mediante la producción y la reproducción auditiva; fomentar la familiarización melódica con la interpretación de bellas canciones para favorecer la memoria y la entonación, y estimular la conciencia sensorial, afectiva y mental sonora como paso previo a la intelectualización de la experiencia musical y su interpretación en el código o lenguaje musical (Willems, 2001, 67). La importancia de desarrollar un "buen oído” para el ejercicio de la creatividad musical hace suponer que la experiencia musical tendrá un significado más profundo si cultivamos la capacidad de escuchar atentamente. En este sentido, consideramos la escucha como un acto creativo cuando favorece la recreación mental sonora de la información recibida para transformarla en algo nuevo. Así, la escucha creativa trasciende la dimensión cotidiana, pues trata de aprovechar la oportunidad de convertir esa información de lo ordinario en extraordinario Por tanto, entendemos la escucha creativa como un factor clave en el acto creativo, tanto en la interpretación e invención de la música, como en la apreciación del aficionado que asiste a conciertos o escucha discos, ya que exige un esfuerzo de su imaginación que le permite reconstruir el mundo sonoro del compositor de un modo subjetivo (Paynter, 1999, 13). En el aula, procurar un ambiente creativo supone promocionar un entorno atractivo, generador de ideas en el que el alumno se sienta libre para pensar y experimentar a su modo, y al mismo tiempo, confiado para sentir la aceptación y la valoración de su aportación como una forma de identidad y expresión personal. Un entorno que al mismo tiempo funciona como elemento catalizador del proceso educativo con la promoción natural de la participación de todos los 
alumnos, procurando la motivación y la iniciativa de los más introvertidos y la canalización del pensamiento creativo de aquellos que son más impulsivos.

\section{Problema de la investigación}

El aprendizaje musical del alumno de Educación Primaria en la práctica creativa requiere la comprensión docente de los elementos musicales que integran sus producciones, como indicador de evaluación fundamental para la orientación del proceso educativo musical individual.

\section{Objetivos}

Nuestro objetivo principal es desarrollar una estrategia metodológica docente que permita evaluar la producción musical creativa del alumno para identificar las dificultades propias del proceso de aprendizaje musical.

El trabajo de este objetivo principal es concretado en los siguientes objetivos específicos:

1. Analizar los elementos musicales y las categorías que integran las producciones musicales de los discentes como contribución al estudio de la evolución del aprendizaje musical del alumno.

2. Describir la relación que ejerce la práctica creativa musical en el desarrollo motivacional y en la autonomía de los estudiantes.

3. Desarrollar un instrumento de evaluación de la actividad creativa musical que permita analizar el nivel de comprensión y expresión musical del alumno.

\section{Metodología}

Nuestra investigación educativa obedece a una metodología de investigación cualitativa enmarcada en un paradigma de naturaleza sociocrítica. La intervención inductiva del docente investigador en el entorno del aula, permite entender este estudio empírico basado en el análisis del proceso educativo musical del alumno en la práctica creativa como principio didáctico fundamental que facilita la evaluación del aprendizaje musical del alumno y orienta la mejora de la práctica docente.

\section{Tipo de investigación}

El diseño de la investigación con un grupo-clase de $4^{\circ}$ de Educación Primaria convierte este tipo de trabajo durante dos cursos escolares en un estudio de caso único en el que el análisis descriptivo del aprendizaje musical en la práctica creativa orienta la actividad investigadora sobre la recogida objetiva de los datos en la actividad cotidiana en el aula, cuyo estudio configura la base epistemológica que ayuda a establecer el diseño de 
un instrumento de evaluación sobre la comprensión y la interpretación del conocimiento musical del alumno.

\section{Métodos de investigación}

El uso de la etnografía como método de investigación fundamental del estudio sugiere la consideración de alternativas teóricas y prácticas que procuran la mejora de la intervención pedagógica en el contexto de la investigación educativa. El trabajo en un escenario natural, el problema objeto de estudio basado en el análisis de la práctica creativa musical, nacido del propio contexto educativo como una necesidad de experimentar la música de manera sensorial y como una experiencia previa a su intelectualización, la observación directa por parte del etnógrafo, la presencia en el campo de estudio durante un período prolongado y el manejo de un gran volumen de datos durante la evolución del estudio han sido las principales características de nuestra investigación.

Por su parte, la investigación-acción emprendida por el docenteinvestigador en el escenario de estudio con el diseño, el desarrollo y la evaluación de esta propuesta educativa fundamentada en el estudio de la práctica creativa muscial facilita el desarrollo de un tipo de investigación evaluativa que además es educativa.

Asimismo, consideramos el uso de la investigación evaluativa como un modo de recogida de información y análisis del conocimiento musical en la práctica creativa. El estudio del diseño de un instrumento de evaluación y su adaptación al contexto de investigación seleccionado, la reflexión y la toma de decisiones que requieren el ajuste del mismo a las necesidades didácticas y la comprensión de la dinámica interna que genera su aplicación en el contexto analizado, caracterizan esta metodología de investigación evaluativa fundamentada en el estudio sistemático del análisis de la información valiosa, válida y fiable, obtenida en una experiencia didáctica de creatividad musical, orientada a mejorar la evaluación de los aprendizajes musicales del alumno y la intervención docente en el proceso educativo.

\section{Técnicas e instrumentos para recolección y tratamiento de datos}

La naturaleza cualitativa de nuestra investigación ha requerido el uso de un conjunto de técnicas y artefactos en la recogida de información como son: la observación participante, la entrevista etnográfica, el analista externo de datos audiovisuales, el diario de campo y la grabación de las sesiones en video.

Como docente e investigador hemos dirigido y formado parte del proceso educativo con la dinamización de cada experiencia, además de observar y recopilar los datos más relevantes surgidos durante la investigación. En este sentido, la observación participante nos ha implicado 
el ejercicio analítico desde una doble perspectiva: holística observacional, basada en el registro objetivo de los datos, y ejecutiva de intervención, fundamentada en el desarrollo del ejercicio docente en el escenario de estudio.

La entrevista etnográfica del maestro-investigador a los alumnos en el trabajo de campo ha estimulado la reflexión y el análisis crítico de los participantes sobre los contenidos musicales que describen sus producciones musicales y las de sus compañeros. Su consideración ha resultado ser un instrumento útil de recogida de información y un recurso didáctico significativo capaz de motivar la atención e intervención activa del participante en la construcción del conocimiento musical de manera personal y cooperativa.

Si bien es cierto que la finalidad de diseñar un instrumento de evaluación de los aprendizajes musicales trata de facilitar el análisis de los diferentes aspectos musicales que integran las producciones de los alumnos, el carácter efímero de la producción musical ha requerido el registro de la información en el escenario de estudio mediante la toma de notas de datos relevantes; la grabación de las sesiones en video, cuya visualización y repetición ha facilitado el análisis de aquellos datos inadvertidos en el momento de su producción y el uso de un diario de campo, cuyo seguimiento ha orientado el análisis de la evolución del estudio y ha contribuido a la concreción del diseño de la herramienta metodológica de la evaluación didáctica de la práctica creativa musical de los alumnos participantes en esta investigación.

Por otra parte, la visualización e interpretación que el analista externo y docente musical ha realizado en el análisis de las sesiones ha proporcionado una nueva visión en la estudio de los aprendizajes de los alumnos que ha favorecido la evaluación objetiva de los mismos y ha supuesto una contribución personal en el diseño de la pauta de evaluación de la práctica creativa musical.

\section{Población y Muestra}

La muestra de nuestro estudio la constituye un grupo clase de 26 alumnos de $4^{\circ}$ curso de Educación Primaria del Colegio Público de Educación Infantil y Primaria Juan XXIII de Zaragoza (España) cuya distribución atiende al siguiente orden:

Tabla 1. Participantes en la investigación

\begin{tabular}{|c|c|c|}
\hline Componentes & Frecuencia & Porcentaje \\
\hline Niñas & 15 & 57,7 \\
\hline Niños & 11 & 42,3 \\
\hline TOTAL & 26 & 100 \\
\hline
\end{tabular}

Fuente: Secretaría de CEIP Juan XXIII

Autor: Luis del Barrio 
Tabla 2. Análisis de la edad de los participantes

\begin{tabular}{|c|c|c|}
\hline Edad/años & Frecuencia & Porcentaje \\
\hline 8 & 4 & 15,4 \\
\hline 9 & 17 & 65,4 \\
\hline 10 & 5 & 19,2 \\
\hline TOTAL & 26 & 100 \\
\hline
\end{tabular}

Fuente: Secretaría de CEIP Juan XXIII

Autor: Luis del Barrio

En el nivel de $4^{\circ}$ de Primaria, los niños con 10 años de edad no han promocionado en algún curso durante la etapa escolar, mientras que los niños de 8 años, todavía no habían cumplido los 9 en el momento del inicio del estudio.

\section{Análisis de resultados}

El análisis de las características musicales de las producciones de los niños y sus aportaciones educativas ha suscitado el diseño de una pauta de evaluación del aprendizaje creativo musical. La aplicación de este trabajo durante dos cursos escolares ha orientado el ejercicio de la praxis docente en el estudio y la selección de una serie de categorías de análisis musical como son: título de la actividad; contenidos trabajados; creación; ritmo; melodía; armonía; forma; carácter y observaciones, en las que se han integrado un conjunto de indicadores de evaluación de los parámetros musicales.

La finalidad didáctica, la atención a los contenidos musicales y textuales, la incorporación de elementos propios y la iniciativa del autor han marcado la evolución de la autonomía del alumno en la actividad creativa musical. A lo largo de los seis trimestres desarrollamos un total de 60 tareas creativas, 10 por trimestre. Según el cuadro 1, la familiarización del niño con la actividad creativa se fundamenta inicialmente en una mayor atención del alumno a la finalidad didáctica, en tareas creativas estructuradas, dirigidas por el docente, cuya evolución es inversamente proporcional al grado de iniciativa y autonomía que el niño va adquiriendo de manera progresiva en el trabajo creativo y, en definitiva, en la naturalidad para abordar con confianza y decisión cada una de las tareas musicales propuestas. Durante el estudio, el niño asume una mayor responsabilidad en la incorporación de elementos propios, en la organización y en la dirección de sus obras. 
Cuadro 1. Evolución de los factores que determinan la autonomía del alumno en las tareas creativas musicales
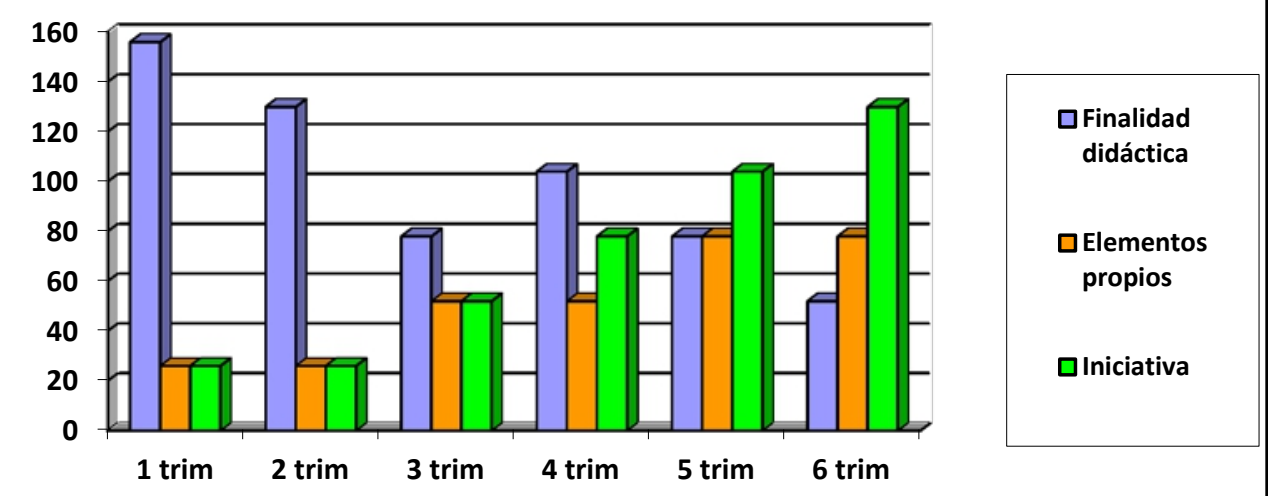

Autor: Luis del Barrio

En la categoría de análisis denominada creación, los factores o indicadores de evaluación que definen las características organizativas de las producciones musicales de los alumnos quedan detalladas en la tabla 3.

Tabla 3. Indicadores de evaluación creativa de las características organizativas de las producciones musicales

\begin{tabular}{|c|c|c|}
\hline Categoría & Indicador evaluativo & Descripción de valoración \\
\hline \multirow{11}{*}{ CREACIÓN } & Participación & Activa, Pasiva, No participación \\
\hline & Tipo de agrupamiento & Individual, pareja, pequeño grupo, gran grupo \\
\hline & Medio de expresión & $\begin{array}{c}\text { Corporal, vocal e instrumental (convencional, } \\
\text { no convencional) }\end{array}$ \\
\hline & Modalidad creativa & $\begin{array}{l}\text { Ritmo corporal, ritmo instrumental } \\
\text { Melodía vocal, melodía instrumental } \\
\text { Canción, Otros }\end{array}$ \\
\hline & Lenguaje musical & Convencional, no convencional \\
\hline & Estructura & Métrica, métrico-tonal, otros \\
\hline & Elemento predominante & Ritmo, melodía, texto, armonía, otros \\
\hline & Sistema de registro & $\begin{array}{l}\text { Ritmo memorizado, ritmo escrito } \\
\text { Melodía memorizada, melodía escrita } \\
\text { Texto memorizado, texto escrito } \\
\text { Editor, Grabadora, Móvil, Otros }\end{array}$ \\
\hline & Lugar de elaboración & Hogar, aula, recreo, otros \\
\hline & Proceso de elaboración & $\begin{array}{c}\text { Patrón-motivo rítmico o melódico } \\
\text { Texto, música } \\
\text { Música escrita, texto } \\
\text { Idea musical } \\
\text { Otros }\end{array}$ \\
\hline & Duración de la obra & -20 seg; 20-40 seg; 40seg-1 min; +1 minuto \\
\hline
\end{tabular}

Autor: Luis del Barrio 
Los factores o indicadores de evaluación de los elementos rítmicos de la producción quedan recogidos en la tabla 4.

Tabla 4. Indicadores de la evaluación creativa de las características rítmicas

\begin{tabular}{|c|c|c|}
\hline Categoría & Indicador evaluativo & Descripción de valoración \\
\hline \multirow{4}{*}{ RITMO } & $\begin{array}{c}\text { Figuras y } \\
\text { elementos rítmicos }\end{array}$ & $\begin{array}{c}\text { Detalle de las figuras convencionales o } \\
\text { signos rítmicos no convencionales }\end{array}$ \\
\cline { 2 - 3 } & $\begin{array}{c}\text { Uso de silencios } \\
\text { Descripción }\end{array}$ & $\begin{array}{c}\text { Si , No } \\
\text { Tipos y representación }\end{array}$ \\
\cline { 2 - 3 } & Intención del silencio & Musical, Expresivo, Cambio \\
\cline { 2 - 3 } & Modalidad creativa & $\begin{array}{c}\text { Ritmo corporal, ritmo instrumental } \\
\text { Melodía vocal, melodía instrumental } \\
\text { Canción, Otros_conos }\end{array}$ \\
\cline { 2 - 3 } & Tempo & Único, Con variaciones (intencionadas o no) \\
\cline { 2 - 3 } & Tipo de tempo & Adagio, Andante, Moderato, Allegro, Vivace \\
\hline
\end{tabular}

Autor: Luis del Barrio

En cuanto a los indicadores de evaluación referentes a los elementos melódicos de las producciones quedan recogidos en la tabla 5.

Tabla 5. Indicadores de la evaluación creativa de las características melódicas

\begin{tabular}{|c|c|c|}
\hline Categoría & Indicador evaluativo & Descripción de valoración \\
\hline \multirow{4}{*}{ MELODÍA } & Origen & Préstamo, Versión, Original \\
\cline { 2 - 3 } & Notas utilizadas & Denominación precisa \\
\cline { 2 - 3 } & Ámbito melódico & Denominación de ámbito \\
\cline { 2 - 3 } & Interválica predominante & Sí (especificar) \\
\cline { 2 - 3 } & Discurso melódico & Grados conjuntos, grados disjuntos \\
\cline { 2 - 3 } & Tonalidad & Mayor, menor, modal, atonal \\
\cline { 2 - 3 } & Cadencia & Sí (especificar) No \\
\cline { 2 - 3 } & Tipo de compás & Binario, ternario, amalgama, sin compás \\
& & determinado \\
\hline
\end{tabular}

Autor: Luis del Barrio

Los factores o indicadores de evaluación de los elementos musicales relacionados con la utilización de la armonía en la producción se recogen en la tabla 6.

Tabla 6. Indicadores de la evaluación creativa del estudio de las características musicales relacionadas con la armonía de las producciones

\begin{tabular}{|c|c|c|}
\hline Categoría & Indicador evaluativo & Descripción de valoración \\
\hline \multirow{3}{*}{ ARMONÍA } & Acordes utilizados & Sí (especificar cuáles) No \\
\cline { 2 - 3 } & Arpegios & Sí (especificar cuáles) No \\
\cline { 2 - 3 } & Grados & Tonales, Modales \\
\cline { 2 - 3 } & & \\
\hline
\end{tabular}

Autor: Luis del Barrio

En cuanto al análisis formal musical, los indicadores que permiten evaluar la estructura de las producciones se recogen en la tabla 7. 
Tabla 7. Indicadores de evaluación del estudio de la forma musical de las producciones

\begin{tabular}{|c|c|c|}
\hline Categoría & Indicador evaluativo & Descripción de valoración \\
\hline \multirow{5}{*}{ FORMA } & Título & Sí (especificar) \\
\hline & $\begin{array}{l}\text { Relación musical } \\
\text { título-obra }\end{array}$ & Mucho, bastante, poco, nada \\
\hline & Idea musical & Sí (Motivo, Semifrase, Frase) No \\
\hline & Estructura general & $\begin{array}{l}\text { Sí (una idea, dos ideas, intro-desarrollo-final, } \\
\text { otros) }\end{array}$ \\
\hline & Estructura musical & $\begin{array}{c}\text { Indefinida, } \\
\text { Monotemática AA', } \\
\text { Bitemática AB, ABA, } \\
\text { Tritemática ABC } \\
\text { Rondó } \\
\text { Tema con variaciones } \\
\text { Otros }\end{array}$ \\
\hline
\end{tabular}

Autor: Luis del Barrio

Atendiendo al análisis y evaluación del carácter y la expresividad de las producciones musicales los factores o indicadores de evaluación se recogen en la tabla 8.

Tabla 8. Indicadores de evaluación del estudio del carácter musical de las producciones

\begin{tabular}{|c|c|c|}
\hline Categoría & Indicador evaluativo & Descripción de valoración \\
\hline \multirow{4}{*}{ CARÁCTER } & Dinámica predominante & pp p mp mf f ff combinación \\
\cline { 2 - 3 } & Originalidad & Mucho, bastante, poco, nada \\
\cline { 2 - 3 } & Dimensión expresiva & Mucho, bastante, poco, nada \\
\cline { 2 - 3 } & Intención- función & $\begin{array}{c}\text { Indefinida, física, emocional, descriptiva, } \\
\text { socializadora, otros }\end{array}$ \\
\hline
\end{tabular}

Autor: Luis del Barrio

A tenor de los resultados obtenidos de las producciones de los alumnos, la última categoría de evaluación denominada Observaciones alberga el análisis cuantitativo de aspectos que tienen que ver con la elaboración, la interpretación y la autoevaluación de la producción. Además, la pauta de evaluación contempla un espacio blanco para una evaluación abierta sobre algún aspecto que requiera un análisis detallado. Los indicadores de evaluación de esta categoría se muestran en la tabla 9. 
Tabla 9. Indicadores de evaluación de la categoría Observaciones referida a la elaboración, interpretación y autoevaluación de la producción musical

\begin{tabular}{|c|c|c|}
\hline Categoría & Indicador evaluativo & Grado de valoración \\
\hline \multirow{5}{*}{ OBSERVACIONES } & Esfuerzo & $\begin{array}{l}\text { 1: muy poco; 2: poco; } 3: \text { normal; 4: } \\
\text { bastante; 5: mucho }\end{array}$ \\
\hline & Motivación & $\begin{array}{l}\text { 1: muy poco; 2: poco; 3: normal; 4: } \\
\text { bastante; 5: mucho }\end{array}$ \\
\hline & $\begin{array}{l}\text { Habilidad vocal, } \\
\text { instrumental }\end{array}$ & $\begin{array}{l}\text { 1: muy poco; 2: poco; 3: normal; 4: } \\
\text { bastante; 5: mucho }\end{array}$ \\
\hline & Seguridad & $\begin{array}{l}\text { 1: muy poco; 2: poco; 3: normal; 4: } \\
\text { bastante; 5: mucho }\end{array}$ \\
\hline & Análisis crítico & $\begin{array}{l}\text { 1: muy poco; 2: poco; 3: normal; 4: } \\
\text { bastante; 5: mucho }\end{array}$ \\
\hline
\end{tabular}

Autor: Luis del Barrio

\section{Conclusión}

La práctica creativa musical como acto natural de expresión ha estimulado el pensamiento musical del alumno, la mejora de la capacidad auditiva, la expresión verbal musical y la capacidad de análisis crítico en el estudio y en la descripción de los elementos, procedimientos y actitudes musicales asociadas a sus producciones y a las de sus compañeros. Si entendemos la pedagogía de la sonoridad como un proceso autodidáctico de feedback gracias al cual el niño aprende a buscar y regular su sonoridad (Delalande, 2013:117), el trabajo creativo en los diferentes medios de expresión ha acercado al niño al mundo sonoro, mediante la exploración y la vivencia dotando de utilidad y significatividad al aprendizaje musical generado en cada experiencia.

Aunque las tareas creativas sujetas a una finalidad didáctica han delimitado las posibilidades expresivas del niño en un contexto de acción determinado, su carácter intencionado ha educado la dirección del pensamiento creativo. Por su parte, la familiarización con la práctica creativa y los recursos adquiridos en la misma han reforzado la autonomía y la confianza del niño para asumir nuevos retos y la seguridad para indagar nuevos modos de expresión desarrollando su capacidad intuitiva y originalidad.

El análisis del conocimiento musical en la práctica creativa ha motivado la necesidad docente de diseñar una herramienta de evaluación capaz de favorecer la comprensión de la musicalidad del niño, de su capacidad expresiva y su dimensión creativa en el escenario de estudio, y ha resultado ser un instrumento didáctico fundamental en la orientación del proceso educativo musical. Aunque la aplicación de la pauta de evaluación de la tarea creativa ha permitido registrar de manera inmediata un buen número de aspectos musicales, de acuerdo con los indicadores de evaluación 
que recogen las distintas categorías de análisis, han sido necesarios el uso de otros instrumentos de observación para lograr una evaluación completa.

La consideración de esta herramienta metodológica ha facilitado la evaluación y el registro del aprendizaje musical en y desde el ejercicio creativo musical.

\section{References:}

1. Cosachov, M. (2000). Entre el cielo y la Tierra. Un viaje por el mapa del conocimiento. Buenos Aires: Biblos.

2. Delalande, F. (1995). La música es un juego de niños. Buenos Aires: Ricordi.

3. Delalande, F. (2013). Las conductas musicales. Santander: Editorial de la Universidad de Cantabria.

4. Díaz, M. y Riaño, E. (2007). Creatividad en educación musical. Santander: Universidad de Cantabria.

5. Finnegan, R. (2007). The Hidden Musicians: Music-making in an English Town (2nd edition). Middletown, CT: Wesleyan University Press.

6. Froehlich, H. C. (2011). Sociología para el profesorado de música. Barcelona: Graó.

7. Glover, J. (2004). Niños compositores (4 a 14 años). Barcelona: Graó.

8. Hallam, S., Creech, A., Varvarigou, M. \& McQueen, H. (2012). Perceived benefits of active engagement with making music in community settings. International Journal of Community Music, 5 (2), 155-174.

9. López Arenosa, E. (2008). La música suena, en Actas del I Congreso Nacional de Educación e Investigación Musical de Metodologías aplicadas y enfoques pedagógicos en la enseñanza musical. Madrid: SEM/ Universidad Autónoma de Madrid.

10. Paynter, J. (1999). Sonido y estructura. Madrid: Akal.

11. Pitts, S. E. (2005). Valuing Musical Participation. Aldershot: Ashgate.

12. Rodríguez Estrada, M. (2005). Manual de Creatividad. Los procesos psíquicos y el desarrollo. México: Trillas.

13. Sloboda, J. (1985). The musical mind: the cognitive psychology of music. Oxford: Clarendon Press.

14. Waisburd, G. y Erdmenger, E. (2007). El poder de la música en el aprendizaje. México: Trillas.

15. Willems, E. (2001). El oído musical. La preparación auditiva del niño. Barcelona: Paidós. 
16. Willems, E. (1976). Les bases psychologiques de l'éducation musicale. $1^{\text {a }}$ édition. Fribourg: Pro Musica.

17. Willems, E. (2011). Las bases psicológicas de la educación musical. Barcelona: Paidós. 